\title{
Cardiovascular Disease Mortality in Relation to Physical Activity during Adolescence and Adulthood in Japan: Does School-Based Sport Club Participation Matter?
}

Krisztina Gero, $\mathrm{MD}, \mathrm{PhD}^{\mathrm{a}}$; Hiroyasu Iso, $\mathrm{MD}, \mathrm{PhD}, \mathrm{MPH}^{\mathrm{b}}$; Akihiko Kitamura, $\mathrm{MD}, \mathrm{PhD}^{\mathrm{c}}$; Kazumasa Yamagishi, MD, $\mathrm{PhD}^{\mathrm{d}}$; Hiroshi Yatsuya, $\mathrm{MD}, \mathrm{PhD}^{\mathrm{e}}$; Akiko Tamakoshi, MD, $\mathrm{PhD}^{\mathrm{f}}$

aDepartment of Social and Behavioral Sciences, Harvard T.H. Chan School of Public Health, Boston, Massachusetts, United States of America, kgero@hsph.harvard.edu ${ }^{b}$ Public Health, Department of Social Medicine, Osaka University Graduate School of Medicine, Suita, Osaka, Japan, iso@ pbhel.med.osaka-u.ac.jp

${ }^{c}$ Research Team for Social Participation and Community Health, Tokyo Metropolitan Institute of Gerontology, Tokyo, Japan, kitamura@pbhel.med.osaka-u.ac.jp ${ }^{\mathrm{d}}$ Department of Public Health Medicine, Faculty of Medicine, University of Tsukuba, Tsukuba, Ibaraki, Japan, yamagishi.kazumas.ge@u.tsukuba.ac.jp

${ }^{\text {e}}$ Department of Public Health, Fujita Health University, Toyoake, Aichi, Japan, yatsuya@fujita-hu.ac.jp

${ }^{f}$ Department of Public Health, Hokkaido University Faculty of Medicine, Sapporo, Japan, tamaa@med.hokudai.ac.jp

Word count for abstract: 247

Word count for main text: 3060

\section{Address for correspondence:}

Krisztina Gero MD, PhD; Department of Social and Behavioral Sciences, Harvard T.H. Chan School of Public Health; Landmark Center West. 401 Park Drive, 4th Floor. Boston, MA. 02215. Tel: +1 617-955-4377. Email: kgero@ @sph.harvard.edu; krisztina.gero@ gmail.com 


\begin{abstract}
We examined potential associations of sport club participation during adolescence and sportsrelated physical activity during adulthood with mortality from cardiovascular diseases (CVD) in a Japanese population. Between 1988 and 1990, 29526 men and 41043 women aged 4079 years responded to a questionnaire including questions about the frequency of sports participation at baseline and sport club participation during junior/senior high school. Subjects were followed-up until the end of 2009, and 4230 cardiovascular deaths (870 CHD, 1859 stroke) were identified. Cox proportional-hazard regression models were used to estimate hazard ratios (HR). During the first-two thirds of the follow-up - where the proportional hazards assumption was met - the multivariate-adjusted HR (95\% confidence interval) for total CVD mortality was 0.77 (0.61-0.98) among men and 0.82 (0.61-1.10) among women who were physically active at baseline ( $\geq 5 \mathrm{~h} /$ week versus $1-2 \mathrm{~h} /$ week). The corresponding HRs for coronary heart disease (CHD) mortality were 0.65 (0.39-1.07) and 0.40 (0.17-0.91), respectively. The combined associations of sports participation during adulthood and adolescence were also examined. Among men who participated in sports for $\geq 5 \mathrm{~h} /$ week at baseline, the multivariate-adjusted HR for those who also engaged in sport club activities during adolescence was 0.89 (0.61-1.30) for total CVD mortality and 0.24 (0.080.71) for CHD mortality when compared to non-participants. Among women, no statistically significant differences were found between sport club participants and non-participants. In conclusion, participating in sport clubs during adolescence might lead to a more pronounced risk-reduction for CHD mortality among men who also participate in sport activities during adulthood.
\end{abstract}

Key Words: physical activity; cardiovascular diseases; coronary disease; primary prevention 


\section{Introduction}

Taking part in cultural or sport club activities during junior/senior high school years is an integral part of Japanese culture. Previous studies reported that participating in school-based organized sport activities was associated with a favorable cardiovascular risk profile in Japanese adolescents, including elevated HDL-cholesterol and adiponectin levels, lower total cholesterol and triglyceride levels, decreased insulin resistance, lower blood pressure, lower body fat percentage, and was negatively associated with smoking and alcohol consumption. ${ }^{1-4}$ Cardiovascular risk factors and risk factor clustering tracking from childhood to adulthood was found to affect the risk of CVD morbidity and mortality in later years. ${ }^{5-17}$ Moderate to vigorous physical activity during adulthood was inversely associated with CVD morbidity and mortality due to improved lipid profile and insulin sensitivity, lowered blood pressure, improved endothelial function, and reduced oxidative stress. ${ }^{18-30}$ While associations of physical activity during adolescence and adulthood were extensively studied separately, there is very little information on the possible combined associations of the two. This study, therefore, examined the associations of participation in school-based sport clubs and physical activity during adulthood on CVD mortality in later years among Japanese in a large-scale population-based cohort study. 


\section{Methods}

\section{Study population and baseline questionnaire}

The data was obtained through the Japan Collaborative Cohort (JACC) Study for Evaluation for Cancer Risk, sponsored by the Japanese Ministry of Education, Science, Sports, and Culture. As part of the JACC study, self-administered questionnaires containing information on medical history and lifestyle factors were collected between 1988 and $1990 .{ }^{31}$ Before filling out the questionnaire, informed individual consent was obtained from each participant in 36 of the 45 study areas (written consent in 35 areas and oral consent in 1 area). In the remaining 9 areas, group consent was obtained from each area leader. ${ }^{31}$ The investigation protocol was approved by the ethics committees of Nagoya University and Osaka University. The number of respondents was 110 585, including 46395 men and 64190 women aged 4079 years. For evaluating sport activity at baseline, the following question was used: "What is the average amount of time you spend engaging in sports on a weekly basis?" The possible answers were " $<1$ hour", "1 to 2 hours", " 3 to 4 hours", and " $\geq 5$ hours". The participants were also asked whether they engaged in sport club activities during junior and senior high school: "Did you participate in sport club activities during junior and senior high schools?" The possible answers were "no", "for a short time", and "yes". The reliability and validity of the questionnaire regarding physical activity were previously reported elsewhere. ${ }^{32}$ After excluding 36019 participants who did not answer the questions of interest and 3997 participants with history of CVD or cancer at baseline, the remaining number of participants was 70569,29526 men and 41043 women.

\section{Mortality surveillance}

In each community, death certificates were forwarded to the local public health center, then mortality data were sent to the Ministry of Health, Labor and Welfare for centralization. The underlying causes of death were coded based on the 10th revision of the International Classification of Diseases (ICD-10). All deaths within the study cohort were confirmed, excluding participants (censored cases) who died after moving out of their original community. In 35 communities, the follow-up was conducted until the end of 2009.

However, in 4 areas the study was terminated at the end of 1999, in 4 other areas at the end of 2003, and in 2 areas at the end of 2008. The average follow-up was 16.4 years. Out of all participants, $24.8 \%$ died and $5.8 \%$ moved away by the end of follow-up. Cause-specific mortality was defined using ICD-10 codes: codes I01-I99 for total CVD mortality, codes I20I25 for coronary heart disease (CHD) mortality, and codes I60-I69 for total stroke mortality. 


\section{Statistical analysis}

Person-years were calculated from the date of study enrollment until the date of death, the date of moving out of the original community, or until the end of the study, whichever happened first. Cox proportional hazards regression models were used to estimate sexstratified age- and multivariate-adjusted hazard ratios (HRs) with 95\% confidence intervals (CIs) for total CVD, CHD, and total stroke mortality. All models were adjusted for age, then multivariate models were further adjusted for other potential confounding factors including history of hypertension (no or yes), history of diabetes (no or yes), body mass index (sexspecific quintiles), alcohol consumption (never, ex-drinker, and current drinker of 1-22, 23 $45,46-68$, and $\geq 69$ grams of ethanol/day), smoking status (never, ex-smoker, and current smoker of $1-19$ or $\geq 20$ cigarettes/day), hours of sleep (<6.0, 6.0-6.9, 7.0-7.9, 8.0-8.9, and $\geq 9$ hours/day), employment status (unemployed or employed, including housewives and retirement), age of completed education ( $<13,13-15,16-18$, and $\geq 19$ years old), perceived level of mental stress (low, normal, high), fish intake (0,<1, 1-2, 3-4, and $\geq 5$ times/week), and time spent walking indoors or outside $(<0.5,0.5,0.6-0.9$, and $\geq 1.0$ hours/day). Since our aim was to study the associations of physical activity in healthy individuals, and those who engage in sport activities for less than an hour per week were more likely to have pre-existing health problems, the reference for sport participation at baseline was set for 1 to 2 hours per week (second lowest category). To examine the combined associations of sport participation at baseline and sport club participation during adolescence, a new variable was created where participants were categorized into four groups.: Group 1 included participants who engaged in $<5$ hours of sports per week at baseline and did not participate in sport club activities during their school years. Group 2 also spent less than 5 hours per week doing sports when interviewed, but they participated in sports clubs for at least a "short time" during their adolescence. Both Group 3 and Group 4 participated in $\geq 5$ hours of sports per week, but while participants in Group 3 - the reference group - did not engage in any sport club activities during their school years, participants in Group 4 joined junior/senior high school sport clubs for at least a "short time". Since the information on physical activity during adulthood was collected only at baseline, we further hypothesized that the predictive power of baseline covariates might change during the long follow-up period, especially in older agegroups. After confirming the violation of the proportional-hazards assumption using tests based on cumulative sums of martingale residuals and interaction terms between sport participation at baseline and follow-up time, separate analyses were performed first for the first two thirds (until the end of 2003), then for the last third of the follow-up period (until the 
end of 2009). In order to avoid the potential confounding resulting from any existing but unreported health disorders, additional analyses were performed after excluding deaths within the first two years of the follow-up period (437 men, 232 women). All analyses were conducted using SAS version 9.4 (SAS Institute Inc., Cary, NC). 


\section{Results}

For this research, 70569 participants of the JACC study (29 526 men and 41043 women) were followed up between 1988 and 2009. During a median of 16.4 follow-up years, 2430 CVD deaths were identified, including 870 CHD and 1859 stroke cases.

Table 1 shows the sex-specific age-standardized characteristics of the participants according to four categories of sport participation at baseline and sport club participation during adolescence. Compared to participants reporting 1-2 hours/week of sport participation at baseline, men and women who did sports for at least 5 hours/week had a higher mean age and were more likely to walk at least 1 hour/day, regardless of sport club participation status. Among men and women who did not participate in school-based sport club activities, participants who reported $\geq 5$ hours/week of sport activity at baseline had higher ethanol intake and were less likely to have collage or higher education compared to those who reported 1-2 hours of weekly sport participation at baseline. Compared to non-participants, men and women participating in sport clubs during adolescence were less likely to be physically inactive ( $<1$ hours/week) and were more likely to do sports for $\geq 3$ hours/week, to have college or higher education, and to be current smokers.

Table 2 indicates the results of the assessment of the proportional hazards assumption for sport-related physical activity at baseline. The violation of the proportional hazards assumption was confirmed among participants who reported engaging in sport activities for $<1$ hour or $\geq 5$ hours per week when interviewed. To deal with the problem of nonproportionality, all further analyses were performed stratified by time. There was no violation of the proportional hazards assumption for the first two thirds of the follow-up period, that is, until the end of 2003.

Table 3 shows sex-specific age- and multivariate-adjusted HRs (95\% confidence interval) for CVD mortality according to sport participation at baseline, stratified by followup time. During the first two thirds of the follow-up period, men reporting $\geq 5$ hours/week of sport activity had a multivariate-adjusted HR of 0.77 (0.61-0.98) for total CVD mortality when compared to those who participated in sports for only 1-2 hours/week. The results for CHD and total stroke mortality showed a similar trend with multivariate-adjusted HRs of $0.65(0.39-1.07)$ and $0.92(0.65-1.30)$, respectively, but these associations did not reach statistical significance. The trend for physically active women ( $\geq 5$ hours/week versus $1-2$ hours/week) was similar with a multivariate-adjusted HR of 0.82 (0.61-1.10) for total CVD, 0.40 (0.17-0.91) for CHD, and 0.65 (0.42-1.01) for stroke mortality. During the last third of 
the follow-up period, the results were not statistically significant. Sport club participation during adolescence in itself (adjusted for sport participation at baseline) was not statistically significantly associated with cardiovascular mortality in later years (data not shown).

Table 4 shows sex-specific HRs for the combined associations of sport club participation during adolescence and sports-related physical activity at baseline, stratified by follow-up time. During the first two thirds of the follow-up period, among men who reported $\geq 5$ hours of sport activity at baseline the risk of CHD mortality for junior/senior high school club participants was lower compared to non-participants. Among physically active ( $\geq 5$ h/week of sports at baseline) men, the multivariate-adjusted HRs (95\% CI) for school-based sport club participants were 0.89 (0.61-1.30) for total CVD, 0.24 (0.08-0.71) for CHD, and $1.26(0.73-2.17)$ for total stroke mortality when compared to non-participants. The corresponding results among physically active women were 1.01 (0.61-1.66) for total CVD and $0.86(0.39-1.89)$ for total stroke mortality. For women in Groups 3 and 4 the number of CHD mortality cases were too few to provide stable hazard ratio estimates. The results for the last third of the follow-up period were not statistically significant.

When excluding study participants who died within two years after baseline inquiry, results did not change considerably (Tables A.1 and A.2). 


\section{Discussion}

The present large cohort study showed that sport club participation during adolescence in itself - without being physically active later in life as well - was not associated with reduced cardiovascular mortality of participants aged 40 years or older. This is in line with previous findings stating that being physically active only during young adulthood do not prevent premature cardiovascular mortality in later years. ${ }^{33}$ However, the multivariate-adjusted risk of CHD mortality among physically active men ( $\geq 5$ hours/week of sports at baseline) was lower for those who participated in school-based sport clubs during their adolescence compared to non-participants. This association was confined to observations in the first two-thirds of the follow-up period, but did not change considerably after excluding deaths within the first two years of follow up.

One possible explanation for the lower CHD mortality risk among long-term physically active men might be a potential long-lasting influence of sport club participation in Japanese schools on physical activity, diet, or other lifestyles in later years. In Japan, extracurricular club activities are considered to be an important part of education. ${ }^{34-36}$ By 1926, around when study participants in the highest age-group reached junior/senior high school age, a wide range of sports were practiced by students. The list of available sports in schools included baseball, tennis, rowing, swimming, gymnastics, sumo, judo, kendo (Japanese fencing), kyudo (Japanese archery), track and field, basketball, football, soccer, handball and volleyball; all of which incorporated vigorous aerobic exercise and resistance training. ${ }^{34}$ In the Japanese society, since the establishment of sport clubs participating students thoroughly devote themselves to sports, practicing at least 6 times per week - mainly after or before school - for at least 3 - 3.5 hours/day in both private and public schools, even during school vacations and holidays. Though more male students join sport clubs than female students (around 60\% versus 40\%), the intensity of the practice is similar for both sexes. ${ }^{35-36}$ Once they have joined, the majority of the students remain members of their chosen clubs throughout their middle school or high school years. ${ }^{35}$ Therefore, participating in high-school-based sport clubs is associated with regular high levels of intensive physical activity including both aerobic and resistance exercises, which meets the requirements of physical activity recommendations and guidelines for this age group. ${ }^{37-38}$

In the published literature, participating in school-based sport clubs was linked to better lipid profiles, decreased insulin resistance, lower blood pressure, and lower body fat percentage compared to non-participants in Japanese adolescents. ${ }^{1-3}$ Similar findings were 
reported based on other - non-Japanese - populations, where physical activity was also positively related in youth to cardiorespiratory fitness, muscular strength, reduction in overall and visceral adiposity, increased bone mineral content and density, and better mental health. ${ }^{37-38}$ It was also shown that CVD risk factors and risk factor clusters might track from adolescence to adulthood increasing the risk of CVD mortality in later years. ${ }^{5-17}$ In our study population, there were no significant differences in mean BMI or in the prevalence of hypertension and diabetes by current or past physical activity status. Also, the evidence for confounding or mediation by these risk factors was very weak in our analyses. However, we did not examine more subtle factors such as detailed lipid profile, body fat percentage, insulin sensitivity, endothelial function, or inflammatory markers; therefore, we cannot evaluate potential differences in cardiovascular risk profiles among groups with different physical activity history.

The level of physical activity during adolescence and participation in organized youth sports were also positively associated with physical activity during young adulthood, attributing to longer years of sustained physical activity, and more beneficial CVD risk profiles. ${ }^{39-41}$ Furthermore, sport club participation and sustained physically active lifestyle were associated with healthier lifestyle choices such as non-smoking and lower alcohol consumption, and a healthier diet with lower saturated fatty acid consumption and higher polyunsaturated to saturated fatty acid ratio. ${ }^{4,39}$ The baseline characteristics of our study subjects showed that school-based sport club participants were indeed more likely to be physically active during adulthood compared to non-participants, however, they were also more likely to be current smokers. In schools, the supervision and mentoring received from adults might lead to better behaviors, but outside of school and during adulthood participating in sport groups might lead to different lifestyle choices, including the habit of smoking. ${ }^{4,} 42$

Similarly to a previous study ${ }^{36}$, our findings also showed that students participating in sports clubs during high school are more likely to pursue higher education compared to those who do not participate in sport club activities, which might lead to better socioeconomic status during adulthood, indirectly affecting CVD mortality in later years.

A limitation of this study is that sport club participation was measured with only one close-ended question, the type of sport club and the exact amount of participation time is unknown. However, the unique social, cultural, and historical background ensured strong intensity and commitment involved in these activities. Once students joined a sport club, they tended to devote themselves to the same club for at least 3 years. ${ }^{35}$ Information on sport participation during adulthood was also only assessed at baseline, which affected the 
predictive power of the Cox regression models most likely due to changes in exercise habits of the study participants during the long follow-up. However, after confirming the violation of the proportional hazards assumption, the analyses were performed stratified by follow-up time. Presenting separate analyses for different periods of time is a well-known and widely accepted method for dealing with nonproportionality. ${ }^{43}$ In the present study, the year 2003 was carefully chosen as the end of the first presented follow-up period for the following reasons: By the end of 2003, follow-up for subjects in 8 participating areas was terminated. Also, the end of 2003 concluded approximately two thirds of a 20-year follow-up period from the baseline. In a previous study of Finish men aged 45-64 years where physical activity was also only assessed at the baseline, high physical activity was associated with lower mortality risk compared to low physical activity during the first two thirds of a 20-year follow-up period, but this association did not hold during the last third of the follow-up time. ${ }^{44}$ Apart from possible changes in exercise habits during follow-up, we also cannot exclude the possibility of the presence of one or more time-dependent confounders or mediators, which might also contributed to the observed differences between the first two thirds and the last third of the follow-up time. It is also possible that as the age of the observed population increased, physical activity was no longer protective against CVD mortality.

Another limitation is the sex-specific small number of subjects in the study ( $\mathrm{n}=1097$ for men and 795 for women) who were physically active both during adolescence and at baseline ( $\geq 5$ hours/week). In men, the small number of CHD cases in Group 4 resulted in inflated hazard ratio estimates with wide $95 \%$ confidence intervals, therefore the obtained results have to be interpreted with caution; we would expect "more probable/more appropriate" HR estimates closer to the upper limit of the $95 \%$ confidence interval. In women, there were too few CHD mortality cases in both Groups 3 and 4 to obtain stable hazard ratio estimates, therefore we could not draw valid conclusions regarding the combined associations of sports participation during adolescence and adulthood with CHD mortality.

\section{Conclusion}

Participating in school-based sport clubs might attribute to lower CHD mortality risks in later years among physically active men. Implementing organized youth sport programs as an extracurricular activity in schools might be an important step towards establishing healthier lifestyle habits, leading to lower risks of adult morbidity and mortality. In addition, since the possible favorable influence of school-based sport club participation - in men - depended on physical activity during adulthood, it is crucial to promote a physically active lifestyle throughout the life-course. 


\section{Acknowledgements}

This work was supported by Grants-in-Aid for Scientific Research from the Ministry of Education, Culture, Sports, Science and Technology of Japan (MEXT) (Monbusho); Grantsin-Aid for Scientific Research on Priority Areas of Cancer; and Grants-in-Aid for Scientific Research on Priority Areas of Cancer Epidemiology from MEXT (MonbuKagaku-sho) (Nos. 61010076, 62010074, 63010074, 1010068, 2151065, 3151064, 4151063, 5151069, 6279102, 11181101, 17015022, 18014011, 20014026, 20390156, and 26293138), Comprehensive Research on Cardiovascular and Life-Style Related Diseases (H26-Junkankitou [Seisaku]Ippan-001and H29-Junkankitou [Seishuu]-Ippan-003), and JSPS KAKENHI Grant Number JP 16H06277. We also received support from Harvard Catalyst | The Harvard Clinical and Translational Science Center (National Center for Research Resources and the National Center for Advancing Translational Sciences, National Institutes of Health Award UL1 TR001102) and financial contributions from Harvard University and its affiliated academic healthcare centers. The content is solely the responsibility of the authors and does not necessarily represent the official views of Harvard Catalyst, Harvard University and its affiliated academic healthcare centers, or the National Institutes of Health.

Conflicts of interest: none. 


\section{References}

1. Yoshinaga M, Hatake S, Tachikawa $\mathrm{T}$, et al. Impact of lifestyles of adolescents and their parents on cardiovascular risk factors in adolescents. J Atheroscler Thromb. 2011;18(11):981-990. [PubMed: 21836372]

2. Kawabe H, Murata K, Shibata H, et al. Participation in school sports clubs and related effects on cardiovascular risk factors in young males. Hypertens Res. 2000;23(3):227232. [PubMed: 10821131]

3. Takasaki Y. Serum lipid levels and factors affecting atherogenic index in Japanese children. J Physiol Anthropol Appl Human Sci. 2005;24(4):511-515. doi: 10.2114/jpa.24.511. [PubMed: 16079609]

4. Takakura M. Relations of participation in organized activities to smoking and drinking among Japanese youth: contextual effects of structural social capital in high school. Int J Public Health. 2015;60(6):679-689. doi: 10.1007/s00038-015-0697-4. [PubMed: 26123654]

5. Kemper HC, Snel J, Verschuur R, Storm-van Essen L. Tracking of health and risk indicators of cardiovascular diseases from teenager to adult: Amsterdam Growth and Health Study. Prev Med. 1990;19(6):642-655. [PubMed: 2263575]

6. Webber LS, Srinivasan SR, Wattigney WA, Berenson GS. Tracking of serum lipids and lipoproteins from childhood to adulthood. The Bogalusa Heart Study. Am J Epidemiol. 1991;133(9):884-899. [PubMed: 2028978]

7. Chen X, Wang Y. Tracking of blood pressure from childhood to adulthood: a systematic review and meta-regression analysis. Circulation. 2008;117(25):31713180. doi: 10.1161/CIRCULATIONAHA.107.730366. [PubMed: 18559702]

8. Toschke AM, Kohl L, Mansmann U, von Kries R. Meta-analysis of blood pressure tracking from childhood to adulthood and implications for the design of intervention trials. Acta Paediatr. 2010;99(1):24-29. doi: 10.1111/j.1651-2227.2009.01544.x. [PubMed: 19839954]

9. Juhola J, Magnussen CG, Viikari JS, et al. Tracking of serum lipid levels, blood pressure, and body mass index from childhood to adulthood: the Cardiovascular Risk in Young Finns Study. J Pediatr. 2011;159(4):584-590. doi: 10.1016/j.jpeds.2011.03.021. [PubMed: 21514597] 
10. Joshi SM, Katre PA, Kumaran K, et al. Tracking of cardiovascular risk factors from childhood to young adulthood - the Pune Children's Study. Int J Cardiol. 2014;175(1):176-178. doi: 10.1016/j.ijcard.2014.04.105. [PubMed: 24874906]

11. Simmonds M, Llewellyn A, Owen CG, Woolacott N. Predicting adult obesity from childhood obesity: a systematic review and meta-analysis. Obes Rev. 2016;17(2):95107. doi: 10.1111/obr.12334. [PubMed: 26696565]

12. Andersen LB, Hasselstrøm H, Grønfeldt V, Hansen SE, Karsten F. The relationship between physical fitness and clustered risk, and tracking of clustered risk from adolescence to young adulthood: eight years follow-up in the Danish Youth and Sport Study. Int J Behav Nutr Phys Act. 2004;1(1):6. doi: 10.1186/1479-5868-1-6. [PubMed: 15169561]

13. Camhi SM, Katzmarzyk PT. Tracking of cardiometabolic risk factor clustering from childhood to adulthood. Int J Pediatr Obes. 2010;5(2):122-129. doi: 10.3109/17477160903111763. [PubMed: 19593726]

14. Baker JL, Olsen LW, Sørensen TI. Childhood body-mass index and the risk of coronary heart disease in adulthood. N Engl J Med. 2007;357(23):2329-2337. doi: 10.1056/NEJMoa072515. [PubMed: 18057335]

15. Morrison JA, Glueck CJ, Wang P. Childhood risk factors predict cardiovascular disease, impaired fasting glucose plus type 2 diabetes mellitus, and high blood pressure 26 years later at a mean age of 38 years: the Princeton-lipid research clinics follow-up study. Metabolism. 2012;61(4):531-541. doi: 10.1016/j.metabol.2011.08.010. [PubMed: 22001337]

16. Morrison JA, Glueck CJ, Woo JG, Wang P. Risk factors for cardiovascular disease and type 2 diabetes retained from childhood to adulthood predict adult outcomes: the Princeton LRC Follow-up Study. Int J Pediatr Endocrinol. 2012;2012(1):6. doi: 10.1186/1687-9856-2012-6. [PubMed: 22507454]

17. Llewellyn A, Simmonds M, Owen CG, Woolacott N. Childhood obesity as a predictor of morbidity in adulthood: a systematic review and meta-analysis. Obes Rev. 2016;17(1):56-67. doi: 10.1111/obr.12316. [PubMed: 26440472]

18. Noda $\mathrm{H}$, Iso $\mathrm{H}$, Toyoshima $\mathrm{H}$, et al. Walking and sports participation and mortality from coronary heart disease and stroke. J Am Coll Cardiol. 2005;46(9):1761-1767. doi:10.1016/j.jacc.2005.07.038. [PubMed: 16256882]

19. Sofi F, Capalbo A, Cesari F, Abbate R, Gensini GF. Physical activity during leisure time and primary prevention of coronary heart disease: an updated meta-analysis of 
cohort studies. Eur J Cardiovasc Prev Rehabil. 2008;15(3):247-257. doi: 10.1097/HJR.0b013e3282f232ac. [PubMed: 18525378]

20. Sattelmair J, Pertman J, Ding EL, et al. Dose response between physical activity and risk of coronary heart disease: a meta-analysis. Circulation. 2011;124(7):789-795. doi: 10.1161/CIRCULATIONAHA.110.010710. [PubMed: 21810663]

21. Koba S, Tanaka H, Maruyama C, et al. Physical activity in the Japan population: association with blood lipid levels and effects in reducing cardiovascular and allcause mortality. J Atheroscler Thromb. 2011;18(10):833-845. doi: 10.5551/jat.8094. [PubMed: 21946534]

22. Lee IM, Paffenbarger RS Jr. Preventing coronary heart disease: the role of physical activity. Phys Sportsmed. 2001;29(2):37-52. doi: 10.3810/psm.2001.02.366. [PubMed: 20086562]

23. Kraus WE, Houmard JA, Duscha BD, et al. Effects of the amount and intensity of exercise on plasma lipoproteins. N Engl J Med. 2002;347(19):1483-1492. doi: 10.1056/NEJMoa020194. [PubMed: 12421890]

24. Sarzynski MA, Burton J, Rankinen T, et al. The effects of exercise on the lipoprotein subclass profile: A meta-analysis of 10 interventions. Atherosclerosis. 2015;243(2):364-372. doi: 10.1016/j.atherosclerosis.2015.10.018. [PubMed: 26520888]

25. Houmard JA, Tanner CJ, Slentz CA, et al. Effect of the volume and intensity of exercise training on insulin sensitivity. J Appl Physiol (1985). 2004;96(1):101-106. doi: 10.1152/japplphysiol.00707.2003. [PubMed: 12972442]

26. Jarvie JL, Whooley MA, Regan MC, Sin NL, Cohen BE. Effect of physical activity level on biomarkers of inflammation and insulin resistance over 5 years in outpatients with coronary heart disease (from the Heart and Soul Study). Am J Cardiol. 2014;114(8):1192-1197. doi: 10.1016/j.amjcard.2014.07.036. [PubMed: 25173442]

27. Whelton SP, Chin A, Xin X, He J. Effect of aerobic exercise on blood pressure: a meta-analysis of randomized, controlled trials. Ann Intern Med. 2002;136(7):493503. doi:10.7326/0003-4819-136-7-200204020-00006 [PubMed: 11926784]

28. Börjesson M, Onerup A, Lundqvist S, Dahlöf B. Physical activity and exercise lower blood pressure in individuals with hypertension: narrative review of $27 \mathrm{RCTs}$. $\mathrm{Br} J$ Sports Med. 2016;50(6):356-361. doi: 10.1136/bjsports-2015-095786 [PubMed: 26787705] 
29. Seals DR, Desouza CA, Donato AJ, Tanaka H. Habitual exercise and arterial aging. J Appl Physiol (1985). 2008;105(4):1323-1332. doi: 10.1152/japplphysiol.90553.2008. [PubMed: 18583377]

30. Roque FR, Hernanz R, Salaices M, Briones AM. Exercise training and cardiometabolic diseases: focus on the vascular system. Curr Hypertens Rep. 2013;15(3):204-214. doi: 10.1007/s11906-013-0336-5. [PubMed: 23519745]

31. Tamakoshi A, Ozasa K, Fujino Y, et al. Cohort profile of the Japan Collaborative Cohort Study at final follow-up. J Epidemiol. 2013;23(3):227-232. doi: 10.2188/jea.JE20120161 [PubMed: 23583921]

32. Iwai N, Hisamichi S, Hayakawa N, et al. Validity and reliability of single-item questions about physical activity. J Epidemiol. 2001;11(5):211-218. [PubMed: 11579928]

33. Lakka TA, Bouchard C. Physical Activity, Obesity and Cardiovascular Diseases. In: von Eckardstein A, ed. Atherosclerosis: Diet and Drugs. Verlag Berlin Heidelberg: Springer; 2005:137-163.

34. Kusaka Y. The emergence and development of Japanese school sport. In: Maguire J, Nakayama M, eds. Japan, Sport and Society: Tradition and Change in a Globalizing World. Oxon: Routledge; 2006:19-34.

35. Cave P. Bukatsudo: The educational role of Japanese school clubs. J Jpn Stud. 2004;30(2):383-415. doi: 10.1353/jjs.2004.0041

36. Blackwood T. The educational roles of extracurricular clubs in Japanese schools. In: Okano KH, ed. Nonformal Education and Civil Society in Japan. Oxon: Routledge; 2016:71-91.

37. Physical Activity Guidelines Advisory Committee (PAGAC). Physical Activity Guidelines Advisory Committee Report, 2008 Washington, DC, US Department of Health and Human Services, 2008.

38. Janssen I, Leblanc AG. Systematic review of the health benefits of physical activity and fitness in school-aged children and youth. Int J Behav Nutr Phys Act. 2010;11(7):40. doi: 10.1186/1479-5868-7-40 [PubMed: 20459784]

39. Raitakari OT, Porkka KV, Taimela S, et al. Effects of persistent physical activity and inactivity on coronary risk factors in children and young adults. The Cardiovascular Risk in Young Finns Study. Am J Epidemiol. 1994;140(3):195-205. [PubMed: 8030623] 
40. Kjønniksen L, Anderssen N, Wold B. Organized youth sport as a predictor of physical activity in adulthood. Scand J Med Sci Sports. 2009;19(5):646-654. doi: 10.1111/j.1600-0838.2008.00850.x [PubMed: 18694430]

41. Telama R, Yang X, Leskinen E, et al. Tracking of physical activity from early childhood through youth into adulthood. Med Sci Sports Exerc. 2014;46(5):955-962. doi: 10.1249/MSS.0000000000000181 [PubMed: 24121247]

42. Yamakita M, Kanamori S, Kondo N, Kondo K. Correlates of Regular Participation in Sports Groups among Japanese Older Adults: JAGES Cross-Sectional Study. PLoS One. 2015;10(10):e0141638. doi: 10.1371/journal.pone.0141638 [PubMed: 26512895]

43. Rosner B. Hypothesis Testing: Person-Time Data. In: Rosner B, ed. Fundamentals of Biostatistics. Boston (MA): Cengage Learning; 2016:833-834.

44. Pekkanen J, Marti B, Nissinen A, et al. Reduction of premature mortality by high physical activity: a 20-year follow-up of middle-aged Finnish men. Lancet. 1987;1(8548):1473-1477. [PubMed: 2885461] 
Table 1. Sex-specific age-standardized characteristics of participants by sport participation at baseline and sport club participation during adolescence

\begin{tabular}{|c|c|c|c|c|c|c|c|c|}
\hline & \multicolumn{4}{|c|}{ Not sport club participants } & \multicolumn{4}{|c|}{ Sport club participants } \\
\hline & \multirow[b]{2}{*}{$<\mathbf{1}$} & \multicolumn{7}{|c|}{ Sport participation at baseline (hours/week) } \\
\hline & & 1-2 & $3-4$ & $\geq 5$ & $<1$ & $1-2$ & 3-4 & $\geq 5$ \\
\hline \multicolumn{9}{|l|}{ Men } \\
\hline No. at risk & 11680 & 1827 & 808 & 844 & 8772 & 3177 & 1321 & 1097 \\
\hline Percentage at risk & 77 & 12 & 5 & 6 & 61 & 22 & 9 & 8 \\
\hline Age, years ${ }^{a}$ & $57.8(9.4)$ & $58.7(10.4)$ & $61.8(10.2)$ & $64.1(8.8)$ & $53.1(9.3)$ & $52.7(10.0)$ & $56.0(11.1)$ & $58.0(10.5)$ \\
\hline Body mass index, $\mathrm{kg} / \mathrm{m}^{2}$ & $22.5(2.8)$ & $22.6(2.6)$ & $22.9(2.7)$ & $22.9(2.9)$ & $22.9(2.8)$ & $22.9(2.7)$ & $23.0(2.7)$ & $22.9(2.7)$ \\
\hline History of hypertension, \% & 15 & 17 & 16 & 17 & 15 & 16 & 15 & 19 \\
\hline History of diabetes, $\%$ & 4 & 7 & 7 & 6 & 5 & 6 & 5 & 6 \\
\hline Ethanol intake, grams/day & $34.8(22.9)$ & $32.3(21.6)$ & $33.3(24.1)$ & $38.9(26.1)$ & $34.8(22.6)$ & $32.6(21.7)$ & $32.4(21.0)$ & $33.8(22.0)$ \\
\hline Hours of sleep, hours/day & $7.5(1.1)$ & $7.4(1.0)$ & $7.4(1.0)$ & $7.6(1.1)$ & $7.4(1.1)$ & $7.4(1.0)$ & $7.4(1.0)$ & $7.5(1.0)$ \\
\hline Current smoker, $\%$ & 50 & 44 & 46 & 47 & 55 & 51 & 50 & 50 \\
\hline Fish intake $\geq 1$ time/week, $\%$ & 80 & 81 & 81 & 80 & 82 & 82 & 83 & 83 \\
\hline College or higher education, $\%$ & 10 & 15 & 13 & 10 & 19 & 26 & 25 & 23 \\
\hline Unemployed, \% & 13 & 17 & 17 & 16 & 12 & 16 & 15 & 16 \\
\hline High perceived mental stress, $\%$ & 19 & 18 & 21 & 21 & 22 & 21 & 19 & 19 \\
\hline Walking $1 \mathrm{~h}$ /day or more, $\%$ & 45 & 42 & 40 & 76 & 42 & 41 & 42 & 68 \\
\hline \multicolumn{9}{|l|}{ Women } \\
\hline No. at risk & 21196 & 2854 & 1135 & 948 & 10406 & 2705 & 1004 & 795 \\
\hline Percentage at risk & 81 & 11 & 4 & 4 & 70 & 18 & 7 & 5 \\
\hline Age, years ${ }^{\mathrm{a}}$ & $57.7(9.7)$ & $58.4(9.8)$ & $61.7(9.5)$ & $63.1(8.9)$ & $52.8(9.1)$ & $53.3(9.62)$ & $55.1(10.2)$ & $58.8(10.2)$ \\
\hline Body mass index, $\mathrm{kg} / \mathrm{m}^{2}$ & $22.9(3.2)$ & $22.8(3.0)$ & $22.9(3.1)$ & $22.9(3.2)$ & $23.0(3.1)$ & $23.0(2.8)$ & $22.9(3.0)$ & $22.8(3.0)$ \\
\hline History of hypertension, \% & 17 & 19 & 16 & 21 & 18 & 18 & 16 & 16 \\
\hline History of diabetes, $\%$ & 3 & 4 & 5 & 4 & 3 & 3 & 2 & 4 \\
\hline Ethanol intake, grams/day & $10.4(13.7)$ & $9.7(13.8)$ & $9.5(11.0)$ & $12.4(13.3)$ & $10.7(13.6)$ & $9.5(10.6)$ & $10.1(15.1)$ & $10.0(15.68)$ \\
\hline Hours of sleep, hours/day & $7.1(1.1)$ & $7.1(1.1)$ & $7.1(1.0)$ & $7.2(1.1)$ & $7.0(1.0)$ & $7.0(1.0)$ & $7.0(1.0)$ & $7.0(1.0)$ \\
\hline Current smoker, $\%$ & 4 & 3 & 4 & 3 & 5 & 4 & 5 & 5 \\
\hline Fish intake $\geq 1$ time/week, $\%$ & 83 & 83 & 83 & 82 & 85 & 83 & 84 & 83 \\
\hline
\end{tabular}




\begin{tabular}{lccccccc} 
College or higher education, \% & 7 & 11 & 11 & 7 & 12 & 14 & 15 \\
Unemployed, \% & 17 & 18 & 18 & 19 & 14 & 16 & 15 \\
High perceived mental stress, \% & 18 & 18 & 17 & 18 & 19 & 16 & 16 \\
Walking 1h/day or more, \% & 44 & 46 & 50 & 73 & 45 & 46 & 52 \\
\hline
\end{tabular}

Values are means(SD) or percentages and are standardized to the sex-specific age distribution of the study population.

${ }^{a}$ Value is not age adjusted. 
Table 2. Assessment of the proportional hazards assumption with time interactions for sports participation at baseline ${ }^{\mathrm{a}}$

\section{Follow-up from baseline until the end of 2009}

Follow-up from baseline until the end of 2003

Sport participation at baseline (hours/week) ${ }^{\mathrm{x}}$ time

\begin{tabular}{|c|c|c|c|c|c|c|c|c|}
\hline & $<1^{x}$ time & $1-2^{x}$ time & $3-4^{x}$ time & $\geq 5^{x}$ time & $<1^{\mathrm{x}}$ time & $1-2^{x}$ time & 3-4 $4^{x}$ time & $\geq 5^{x}$ time \\
\hline Total CVD & $0.98(0.97-1.00)^{b}$ & 1.0 & $1.00(0.98-1.03)$ & $1.01(0.99-1.04)$ & $0.99(0.96-1.02)$ & 1.0 & $0.99(0.94-1.03)$ & $1.04(0.99-1.09)$ \\
\hline $\mathrm{CHD}$ & $1.01(0.97-1.04)$ & 1.0 & $1.02(0.96-1.07)$ & $1.06(1.00-1.13)^{\mathrm{c}}$ & $1.03(0.97-1.09)$ & 1.0 & $1.00(0.91-1.10)$ & $1.03(0.92-1.15)$ \\
\hline Total stroke & $0.98(0.95-1.00)$ & 1.0 & $1.01(0.97-1.04)$ & $1.02(0.98-1.06)$ & $0.98(0.94-1.02)$ & 1.0 & $0.98(0.91-1.04)$ & $1.07(0.99-1.15)$ \\
\hline
\end{tabular}

${ }^{\mathrm{a}}$ Models were adjusted for age and sex.

${ }^{\mathrm{b}} \mathrm{p}=0.03$

${ }^{c} \mathrm{p}<0.05$ 
Table 3. Sex-specific HRs (95\% CI) for CVD mortality according to sport participation at baseline, stratified by follow-up time

\section{Sport participation at baseline (hours/week)}

$<1$

\section{Men}

Person-years

N

Total CVD

Age-adjusted HR

Multivariate HRa

CHD

Age-adjusted HR

Multivariate HRa

Total stroke

Age-adjusted HR

Multivariate HRa

\section{Women}

Person-years

N

Total CVD

Age-adjusted HR

Multivariate $\mathrm{HR}^{\mathrm{a}}$

CHD

Age-adjusted HR

Multivariate $\mathrm{HR}^{\mathrm{a}}$

Total stroke

Age-adjusted HR
Multivariate $\mathrm{HR}^{\mathrm{a}}$

\section{$1-2$}

$\begin{array}{cc}64787 & 26836 \\ 5004 & 2129 \\ 220 & 128\end{array}$

24613
1941
110

$0.99(0.80-1.23) \quad 0.76(0.61-0.96)$

$0.98(0.79-1.22) \quad 0.77(0.61-0.98)$

29

22

$0.93(0.59-1.46) \quad 0.64(0.39-1.05)$

$0.93(0.59-1.46) \quad 0.65(0.39-1.07)$

65

53

$1.26(0.91-1.74) \quad 0.91(0.65-1.28)$

$1.24(0.89-1.71) \quad 0.92(0.65-1.30)$ $\begin{array}{cc}31602 & 143\end{array}$

$1.21(1.01-1.44) \quad 1.0$

$1.03(0.86-1.23) \quad 1.0$

n $\quad 168 \quad 28$

$1.13(0.76-1.68) \quad 1.0$

$0.94(0.62-1.41) \quad 1.0$

n $\quad 444 \quad 75$

$1.10(0.86-1.40) \quad 1.0 \quad 0.84(0.56-1.27) \quad 0.72(0.47-1.11)$

$0.92(0.72-1.18) \quad 1.0 \quad 0.79(0.52-1.19) \quad 0.65(0.42-1.01)$

\section{3-4}

$<1$

$<1$

74331
13548
498

$0.99(0.81-1.20)$

$0.93(0.76-1.14)$

130

$1.08(0.72-1.61)$

$1.01(0.67-1.52)$

191

$0.95(0.69-1.30)$

$0.88(0.64-1.22)$

$$
\begin{gathered}
123019 \\
21712
\end{gathered}
$$

587
$1.02(0.84-1.25)$

$0.97(0.79-1.19)$

101

$1.09(0.66-1.80)$

$0.99(0.59-1.64)$

233

$1.07(0.77-1.49)$

$1.01(0.72-1.41)$

\section{1-2}

18802
3380
123
1.0
1.0
29
1.0
1.0
49
1.0
1.0

18802

3380
123

1.0

1.0

29

1.0

1.0

49

1.0

$0.88(0.66-1.18) \quad 0.87(0.65-1.16)$

14

7

$$
\begin{gathered}
21814 \\
3838 \\
112 \\
1.0 \\
1.0 \\
18 \\
1.0 \\
1.0 \\
42 \\
1.0
\end{gathered}
$$

1.0
3-4

7005

1282

70

$1.13(0.84-1.51) \quad 0.87(0.64-1.18)$

$1.08(0.81-1.46) \quad 0.87$ (0.64-1.18)

$$
14
$$

22

$1.00(0.53-1.90) \quad 1.40(0.80-2.45)$

$0.95(0.50-1.81) \quad 1.55(0.87-2.73)$ 32

23

$1.29(0.82-2.01) \quad 0.79(0.48-1.31)$

$1.26(0.80-1.98) \quad 0.76(0.46-1.26)$

${ }^{\mathrm{a}}$ Multivariate models were further adjusted for cardiovascular risk factors such as BMI, history of diabetes, history of hypertension, smoking status, alcohol consumption, sleeping hours, education, employment status, perceived mental stress, fish intake, and walking time. 
Table 4. Sex-specific HRs (95\% CI) for CVD mortality according to sport participation at baseline and sport club participation during adolescence

Follow-up from baseline until the end of 2003

Follow-up from 2004 until the end of 2009

Sport participation at baseline (hours/week) / Sport club participation during high school years (Yes or No)

\begin{tabular}{|c|c|c|c|c|c|c|c|c|c|}
\hline & & & & & & & & \\
\hline & & $\begin{array}{l}\text { Group1 } \\
(<5 / \mathrm{No}) \\
\end{array}$ & $\begin{array}{l}\text { Group2 } \\
(<5 / \text { Yes })\end{array}$ & $\begin{array}{l}\text { Group3 } \\
(\geq 5 / \mathrm{No}) \\
\end{array}$ & $\begin{array}{l}\text { Group4 } \\
(\geq 5 / \text { Yes }) \\
\end{array}$ & $\begin{array}{l}\text { Group1 } \\
(<5 / \mathrm{No}) \\
\end{array}$ & $\begin{array}{l}\text { Group2 } \\
(<5 / \text { Yes })\end{array}$ & $\begin{array}{l}\text { Group3 } \\
(\geq 5 / \mathrm{No}) \\
\end{array}$ & $\begin{array}{l}\text { Group4 } \\
(\geq 5 / \text { Yes })\end{array}$ \\
\hline \multicolumn{10}{|l|}{ Men } \\
\hline Person-years & & 181226 & 173833 & 10450 & 14163 & 48140 & 51998 & 2280 & 3857 \\
\hline $\mathrm{N}$ & & 14315 & 13270 & 844 & 1097 & 8902 & 9308 & 439 & 711 \\
\hline Total CVD & $\mathrm{n}$ & 833 & 522 & 64 & 46 & 416 & 275 & 28 & 35 \\
\hline Age-adjusted HR & & $1.36(1.05-1.76)$ & $1.37(1.06-1.78)$ & 1.0 & $0.85(0.58-1.24)$ & $1.34(0.91-1.96)$ & $1.25(0.84-1.85)$ & 1.0 & $1.26(0.76-2.06)$ \\
\hline Multivariate $\mathrm{HR}^{\mathrm{a}}$ & & $1.29(1.00-1.68)$ & $1.33(1.02-1.74)$ & 1.0 & $0.89(0.61-1.30)$ & $1.26(0.85-1.85)$ & $1.24(0.83-1.85)$ & 1.0 & $1.26(0.76-2.08)$ \\
\hline CHD & $\mathrm{n}$ & 180 & 119 & 18 & 4 & 99 & 74 & 8 & 14 \\
\hline Age-adjusted HR & & $0.99(0.61-1.61)$ & $1.02(0.62-1.68)$ & 1.0 & $0.25(0.09-0.75)$ & $1.02(0.49-2.10)$ & $1.02(0.49-2.14)$ & 1.0 & $1.66(0.70-3.97)$ \\
\hline Multivariate $\mathrm{HR}^{\mathrm{a}}$ & & $0.92(0.56-1.52)$ & $0.92(0.55-1.54)$ & 1.0 & $0.24(0.08-0.71)$ & $0.82(0.39-1.73)$ & $0.85(0.40-1.81)$ & 1.0 & $1.53(0.63-3.70)$ \\
\hline Total stroke & $\mathrm{n}$ & 393 & 216 & 27 & 26 & 172 & 100 & 8 & 15 \\
\hline Age-adjusted HR & & $1.55(1.05-2.30)$ & $1.39(0.93-2.08)$ & 1.0 & $1.16(0.67-1.98)$ & $1.94(0.95-3.96)$ & $1.60(0.77-3.31)$ & 1.0 & $1.89(0.80-4.45)$ \\
\hline Multivariate $\mathrm{HR}^{\mathrm{a}}$ & & $1.49(1.00-2.21)$ & $1.41(0.93-2.13)$ & 1.0 & $1.26(0.73-2.17)$ & $1.96(0.95-4.03)$ & $1.76(0.84-3.70)$ & 1.0 & $2.09(0.88-4.98)$ \\
\hline \multicolumn{10}{|l|}{ Women } \\
\hline Person-years & & 331792 & 190383 & 12297 & 10552 & 92990 & 59814 & 3126 & 3113 \\
\hline $\mathrm{N}$ & & 25185 & 14115 & 948 & 795 & 16572 & 10407 & 576 & 557 \\
\hline Total CVD & $\mathrm{n}$ & 893 & 249 & 44 & 24 & 547 & 205 & 31 & 18 \\
\hline Age-adjusted HR & & $1.34(0.99-1.81)$ & $1.14(0.83-1.58)$ & 1.0 & $0.93(0.56-1.53)$ & $1.10(0.76-1.58)$ & $1.05(0.72-1.53)$ & 1.0 & $0.82(0.46-1.47)$ \\
\hline Multivariate $\mathrm{HR}^{\mathrm{a}}$ & & $1.26(0.93-1.71)$ & $1.18(0.85-1.63)$ & 1.0 & $1.01(0.61-1.66)$ & $1.10(0.76-1.60)$ & $1.13(0.76-1.66)$ & 1.0 & $0.90(0.50-1.61)$ \\
\hline CHD & $\mathrm{n}$ & 160 & 50 & 3 & 4 & 97 & 34 & 5 & 1 \\
\hline Age -adjusted HR & & $3.57(1.14-11.2)$ & $3.47(1.08-11.1)$ & 1.0 & $2.28(0.51-10.2)$ & $1.18(0.48-2.91)$ & $1.03(0.40-2.66)$ & 1.0 & $0.28(0.03-2.41)$ \\
\hline Multivariate $\mathrm{HR}^{\mathrm{a}}$ & & $3.46(1.10-10.9)$ & $3.62(1.12-11.8)$ & 1.0 & $2.29(0.51-10.3)$ & $1.00(0.40-2.51)$ & $0.83(0.32-2.18)$ & 1.0 & $0.28(0.03-2.45)$ \\
\hline Total stroke & $\mathrm{n}$ & 429 & 123 & 20 & 9 & 225 & 75 & 14 & 7 \\
\hline Age-adjusted HR & & $1.39(0.89-2.18)$ & $1.20(0.75-1.93)$ & 1.0 & $0.76(0.35-1.67)$ & $0.97(0.56-1.66)$ & $0.80(0.45-1.42)$ & 1.0 & $0.70(0.28-1.74)$ \\
\hline Multivariate $\mathrm{HR}^{\mathrm{a}}$ & & $1.35(0.86-2.13)$ & $1.29(0.80-2.10)$ & 1.0 & $0.86(0.39-1.89)$ & $0.96(0.55-1.66)$ & $0.86(0.48-1.56)$ & 1.0 & $0.76(0.30-1.89)$ \\
\hline
\end{tabular}


Sport participation at baseline (hours/week)

\begin{tabular}{|c|c|c|c|c|c|c|c|c|c|}
\hline & & & & & & & & & \\
\hline & & $<1$ & $1-2$ & $3-4$ & $\geq \mathbf{5}$ & $<1$ & $1-2$ & $3-4$ & $\geq 5$ \\
\hline \multicolumn{10}{|l|}{ Men } \\
\hline Person-years & & 263071 & 64715 & 26806 & 24586 & 74331 & 18802 & 7005 & 6137 \\
\hline $\mathrm{N}$ & & 20130 & 4940 & 2102 & 1917 & 13548 & 3380 & 1282 & 1150 \\
\hline Total CVD & $\mathrm{n}$ & 919 & 201 & 122 & 104 & 498 & 123 & 70 & 63 \\
\hline Age-adjusted HR & & $1.17(1.00-1.36)$ & 1.0 & $1.04(0.83-1.30)$ & $0.79(0.62-1.00)^{\mathrm{c}}$ & $0.99(0.81-1.20)$ & 1.0 & $1.13(0.84-1.51)$ & $0.87(0.64-1.18)$ \\
\hline Multivariate $\mathrm{HR}^{\mathrm{b}}$ & & $1.10(0.94-1.28)$ & 1.0 & $1.02(0.81-1.28)$ & $0.79(0.62-1.00)^{\mathrm{c}}$ & $0.93(0.76-1.14)$ & 1.0 & $1.08(0.81-1.46)$ & $0.87(0.64-1.18)$ \\
\hline CHD & $\mathrm{n}$ & 198 & 50 & 28 & 19 & 130 & 29 & 14 & 22 \\
\hline Age-adjusted HR & & $0.99(0.73-1.35)$ & 1.0 & $1.00(0.63-1.58)$ & $0.61(0.36-1.03)$ & $1.08(0.72-1.61)$ & 1.0 & $1.00(0.53-1.90)$ & $1.40(0.80-2.45)$ \\
\hline Multivariate $\mathrm{HR}^{\mathrm{b}}$ & & $0.94(0.69-1.30)$ & 1.0 & $0.98(0.62-1.57)$ & $0.60(0.35-1.03)$ & $1.01(0.67-1.52)$ & 1.0 & $0.95(0.50-1.81)$ & $1.55(0.87-2.73)$ \\
\hline Total stroke & $\mathrm{n}$ & 421 & 81 & 61 & 52 & 191 & 49 & 32 & 23 \\
\hline Age-adjusted HR & & $1.34(1.05-1.70)$ & 1.0 & $1.27(0.91-1.77)$ & $0.96(0.67-1.36)$ & $0.95(0.69-1.30)$ & 1.0 & $1.29(0.82-2.01)$ & $0.79(0.48-1.31)$ \\
\hline Multivariate $\mathrm{HR}^{\mathrm{b}}$ & & $1.25(0.98-1.59)$ & 1.0 & $1.25(0.89-1.75)$ & $0.95(0.67-1.35)$ & $0.88(0.64-1.22)$ & 1.0 & $1.26(0.80-1.98)$ & $0.76(0.46-1.26)$ \\
\hline \multicolumn{10}{|l|}{ Women } \\
\hline Person-years & & 419764 & 73983 & 28169 & 22829 & 123019 & 21814 & 7971 & 6238 \\
\hline $\mathrm{N}$ & & 31425 & 5532 & 2125 & 1729 & 21712 & 3838 & 1429 & 1133 \\
\hline Total CVD & $\mathrm{n}$ & 873 & 135 & 63 & 68 & 587 & 112 & 53 & 49 \\
\hline Age-adjusted HR & & $1.21(1.01-1.45)$ & 1.0 & $0.89(0.66-1.20)$ & $0.92(0.69-1.24)$ & $1.02(0.84-1.25)$ & 1.0 & $0.98(0.71-1.36)$ & $0.87(0.62-1.21)$ \\
\hline CHD & $\mathrm{n}$ & 158 & 27 & 13 & 7 & 101 & 18 & 12 & 6 \\
\hline Age-adjusted HR & & $1.10(0.73-1.66)$ & 1.0 & $0.91(0.47-1.76)$ & $0.47(0.21-1.08)$ & $1.09(0.66-1.80)$ & 1.0 & $1.39(0.67-2.90)$ & $0.67(0.27-1.70)$ \\
\hline Multivariate $\mathrm{HR}^{\mathrm{b}}$ & & $0.91(0.60-1.38)$ & 1.0 & $0.81(0.42-1.58)$ & $0.40(0.17-0.93)$ & $0.99(0.59-1.64)$ & 1.0 & $1.36(0.65-2.84)$ & $0.75(0.29-1.92)$ \\
\hline Total stroke & $\mathrm{n}$ & 421 & 71 & 28 & 29 & 233 & 42 & 25 & 21 \\
\hline Age-adjusted HR & & $1.10(0.86-1.42)$ & 1.0 & $0.76(0.49-1.17)$ & $0.76(0.49-1.17)$ & $1.07(0.77-1.49)$ & 1.0 & $1.25(0.76-2.05)$ & $1.02(0.60-1.72)$ \\
\hline Multivariate $\mathrm{HR}^{\mathrm{b}}$ & & $0.93(0.72-1.20)$ & 1.0 & $0.71(0.46-1.11)$ & $0.69(0.45-1.08)$ & $1.01(0.72-1.41)$ & 1.0 & $1.14(0.69-1.88)$ & $0.99(0.58-1.69)$ \\
\hline
\end{tabular}

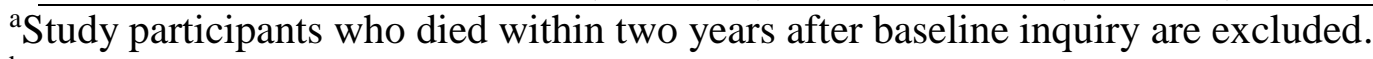

${ }^{\mathrm{b}}$ Multivariate models were further adjusted for cardiovascular risk factors such as BMI, past history of diabetes, past history of hypertension, smoking status, alcohol consumption, sleeping hours, education, employment status, perceived mental stress, fish intake, and walking time.

${ }^{c} \mathrm{p}<0.05$ 
Sport participation at baseline (hours/week) / Sport club participation during high school years (Yes or No)

\begin{tabular}{|c|c|c|c|c|c|c|c|c|c|}
\hline & & & & & & \multirow{2}{*}{\multicolumn{2}{|c|}{$\begin{array}{l}\text { Group2 } \\
(<5 / \text { Yes }) \\
\end{array}$}} & \multirow[b]{2}{*}{$\begin{array}{l}\text { Group3 } \\
(\geq 5 / \mathrm{No}) \\
\end{array}$} & \multirow[b]{2}{*}{$\begin{array}{l}\text { Group4 } \\
(\geq 5 / \text { Yes }) \\
\end{array}$} \\
\hline & & $\begin{array}{l}\text { Group1 } \\
(<5 / \mathrm{No}) \\
\end{array}$ & $\begin{array}{l}\text { Group2 } \\
(<5 / \text { Yes }) \\
\end{array}$ & $\begin{array}{l}\text { Group3 } \\
(\geq 5 / \mathrm{No}) \\
\end{array}$ & $\begin{array}{l}\text { Group4 } \\
(\geq 5 / \text { Yes }) \\
\end{array}$ & & & & \\
\hline \multicolumn{10}{|l|}{ Men } \\
\hline Person-years & & 180938 & 173653 & 10430 & 14156 & 48140 & 51998 & 2280 & 3857 \\
\hline $\mathrm{N}$ & & 14059 & 13113 & 829 & 1088 & 8902 & 9308 & 439 & 711 \\
\hline Total CVD & $\mathrm{n}$ & 766 & 476 & 60 & 44 & 416 & 275 & 28 & 35 \\
\hline Age-adjusted HR & & $1.34(1.03-1.75)$ & $1.34(1.02-1.76)$ & 1.0 & $0.87(0.59-1.28)$ & $1.34(0.91-1.96)$ & $1.25(0.84-1.85)$ & 1.0 & $1.26(0.76-2.06)$ \\
\hline Multivariate $\mathrm{HR}^{\mathrm{b}}$ & & $1.29(0.99-1.69)$ & $1.32(1.00-1.74)$ & 1.0 & $0.90(0.61-1.34)$ & $1.26(0.85-1.85)$ & $1.24(0.83-1.85)$ & 1.0 & $1.26(0.76-2.08)$ \\
\hline CHD & $\mathrm{n}$ & 169 & 107 & 16 & 3 & 99 & 74 & 8 & 14 \\
\hline Age-adjusted HR & & $1.04(0.62-1.75)$ & $1.02(0.60-1.74)$ & 1.0 & $0.21(0.06-0.73)$ & $1.02(0.49-2.10)$ & $1.02(0.49-2.14)$ & 1.0 & $1.66(0.70-3.97)$ \\
\hline Multivariate $\mathrm{HR}^{\mathrm{b}}$ & & $0.98(0.58-1.66)$ & $0.94(0.55-1.63)$ & 1.0 & $0.20(0.06-0.68)$ & $0.82(0.39-1.73)$ & $0.85(0.40-1.81)$ & 1.0 & $1.53(0.63-3.70)$ \\
\hline Total stroke & $\mathrm{n}$ & 361 & 202 & 26 & 26 & 172 & 100 & 8 & 15 \\
\hline Age-adjusted HR & & $1.49(1.00-2.22)$ & $1.36(0.90-2.05)$ & 1.0 & $1.20(0.70-2.07)$ & $1.94(0.95-3.96)$ & $1.60(0.77-3.31)$ & 1.0 & $1.89(0.80-4.45)$ \\
\hline Multivariate $\mathrm{HR}^{\mathrm{b}}$ & & $1.46(0.97-2.18)$ & $1.41(0.92-2.15)$ & 1.0 & $1.32(0.76-2.29)$ & $1.96(0.95-4.03)$ & $1.76(0.84-3.70)$ & 1.0 & $2.09(0.88-4.98)$ \\
\hline \multicolumn{10}{|l|}{ Women } \\
\hline Person-years & & 331584 & 190333 & 12284 & 10545 & 92990 & 59814 & 3126 & 3113 \\
\hline $\mathrm{N}$ & & 25012 & 14070 & 938 & 791 & 16572 & 10407 & 576 & 557 \\
\hline Total CVD & $\mathrm{n}$ & 835 & 236 & 44 & 24 & 547 & 205 & 31 & 18 \\
\hline Age-adjusted HR & & $1.25(0.93-1.70)$ & $1.08(0.78-1.50)$ & 1.0 & $0.93(0.56-1.53)$ & $1.10(0.76-1.58)$ & $1.05(0.72-1.53)$ & 1.0 & $0.82(0.46-1.47)$ \\
\hline Multivariate $\mathrm{HR}^{\mathrm{b}}$ & & $1.17(0.86-1.60)$ & $1.11(0.80-1.54)$ & 1.0 & $1.00(0.61-1.65)$ & $1.10(0.76-1.60)$ & $1.13(0.76-1.66)$ & 1.0 & $0.90(0.50-1.61)$ \\
\hline CHD & $\mathrm{n}$ & 151 & 47 & 3 & 4 & 97 & 34 & 5 & 1 \\
\hline Age -adjusted HR & & $3.39(1.08-10.6)$ & $3.27(1.02-10.5)$ & 1.0 & $2.29(0.51-10.2)$ & $1.18(0.48-2.91)$ & $1.03(0.40-2.66)$ & 1.0 & $0.28(0.03-2.41)$ \\
\hline Multivariate $\mathrm{HR}^{\mathrm{b}}$ & & $3.31(1.05-10.4)$ & $3.51(1.08-11.4)$ & 1.0 & $2.29(0.51-10.3)$ & $1.00(0.40-2.51)$ & $0.83(0.32-2.18)$ & 1.0 & $0.28(0.03-2.45)$ \\
\hline Total stroke & $\mathrm{n}$ & 404 & 116 & 20 & 9 & 225 & 75 & 14 & 7 \\
\hline Age-adjusted HR & & $1.32(0.84-2.06)$ & $1.14(0.71-1.84)$ & 1.0 & $0.76(0.35-1.67)$ & $0.97(0.56-1.66)$ & $0.80(0.45-1.42)$ & 1.0 & $0.70(0.28-1.74)$ \\
\hline Multivariate $\mathrm{HR}^{\mathrm{b}}$ & & $1.27(0.81-2.01)$ & $1.21(0.75-1.97)$ & 1.0 & $0.85(0.39-1.88)$ & $0.96(0.55-1.66)$ & $0.86(0.48-1.56)$ & 1.0 & $0.76(0.30-1.89)$ \\
\hline
\end{tabular}

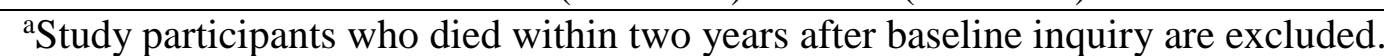

${ }^{\mathrm{b}}$ Multivariate models were further adjusted for cardiovascular risk factors such as BMI, past history of diabetes, past history of hypertension, smoking status, alcohol consumption, sleeping hours, education, employment status, perceived mental stress, fish intake, and walking time. 